\title{
Ausencia y trauma en el ser para-sí: una lectura de la ontología de Jean-Paul Sartre desde Dominick LaCapra
}

\author{
Absence and trauma in the being for-it-self: A \\ reading of Jean-Paul Sartre's ontology from \\ Dominick LaCapra
}

\author{
RAFAEL PÉREZ BAQUERO \\ Universidad de Murcia
}

Recibido: 04/10/2020 Aceptado:25/01/2021

\begin{abstract}
RESUMEN
El objetivo del presente artículo es el de reconstruir algunas de las nociones fundamentales de la ontología fenomenológica sartreana desde las categorías hermenéuticas de la historia intelectual de Dominick LaCapra. Este bagaje conceptual destaca por su fecundidad a la hora de justificar cómo algunos intelectuales de la pasada centuria han metabolizado las experiencias de violencia e incertidumbre de su tiempo en sus propias obras. Con el fin de proyectar estos esquemas interpretativos, reconstruiremos las tesis sartreanas en torno al ser de la conciencia, a la intersubjetividad y al proyecto existencial desde el prisma que ofrecen las reflexiones de LaCapra.
\end{abstract}

\section{PALABRAS CLAVE}

TRAUMA, AUSENCIA, SARTRE, SER PARA-SÍ, INTERSUBJETIVIDAD

\begin{abstract}
This paper aims at delving further into the notions of Sartre's ontological phenomenology by means of hermeneutic analysis provided by Dominick LaCapra's intellectual history. LaCapra's ideas stand out for its potentiality when it comes to address how some intellectuals from the 20th have dealt with the experience of violence and uncertainty stemming from their historical context. With a view to taking forward this hermeneutic background, this paper explores
\end{abstract}

(C) Contrastes. Revista Internacional de Filosofía, vol. XXVI N³ (2021), pp. 89-109. ISSN: 1136-4076 Departamento de Filosofía, Universidad de Málaga, Facultad de Filosofía y Letras Campus de Teatinos, E-29071 Málaga (España) 
Sartre's ideas on the being of consciousness, intersubjectivity and the existential project by endorsing the lens provided by LaCapra's works.

KEYWORDS

TRAUMA, ABSENCE, SARTRE, BEING FOR-IT-SELF, INTERSUBJECTIVITY

\section{INTRODUCCIÓN}

DURANTE LAS ÚLTIMAS DÉCADAS, la denominada «historia intelectual» ha sido objeto tanto de un creciente interés interdisciplinar como de una serie de giros metodológicos respecto a sus premisas a la hora de analizar textos históricos. De la mano de la teoría de género, decolonial, los estudios étnicos... (LaCapra 2009, p. 20), la metodología de la historia intelectual ha explorado con especial ahínco las claves discursivas y los resortes ideológicos que subyacen a la elaboración textos pertenecientes al canon histórico, literario y filosófico occidental. No cabe duda de que estas nuevas tendencias recogen la herencia de parte de corrientes filosóficas del pasado siglo: la hermenéutica, el existencialismo, el estructuralismo, la deconstrucción... De ahí la necesidad, por parte de la historia intelectual, de mantener un diálogo vivo con sus predecesores. Ahora bien, estas conversaciones no versan simplemente sobre la metodología a implementar en la crítica de textos. A su vez, es preciso someter aquellas fuentes filosóficas a un examen crítico similar ya que sus propias obras son producidas en el interior de un contexto concreto y han sido introducidas en un canon cultural, cuyas raíces históricas es preciso sacar a la luz. Un diálogo de esta naturaleza es lo que tratamos de reconstruir en las siguientes líneas. Con el objetivo de profundizar en estas corrientes interpretativas y en su fecundidad para el análisis históricofilosófico articularemos una lectura crítica de algunos de los pasajes de $\mathrm{El} \mathrm{ser}$ y la nada de Jean-Paul Sartre, a partir de la obra contemporánea del teórico Dominick LaCapra.

La prolífica obra del profesor emérito de la Universidad de Cornell ofrece tanto una metodología a la hora de analizar textos del siglo XX, como una pluralidad de lecturas sobre los mismos profundamente interdisciplinar. Aborda tanto obras de naturaleza histórica, literaria, como filosófica. Pese a que su objeto de investigación en los últimos años se haya focalizado en la primera, «la historia no se puede separar completamente de la literatura y la filosofía [...] aunque tampoco pueda identificarse con ellas» (Kramer 1989, p. 104). Desde un primer momento, LaCapra define el objeto del historiador intelectual como el análisis de las relaciones entre los textos y sus contextos de pertenencia (1983, p. 35). Ahora bien, ello no obsta para 
adoptar un contextualismo historicista que simplifique la interpretación a la mera «explicación de todos los textos como documentos que son vistos predominantemente como síntomas objetivados o expresiones directas de sus contextos» (2009, p. 16). La adopción de dicho contextualismo por la historia social contemporánea simplifica la complejidad real de la experiencia histórica, interpretando textos y contextos unidimensionalmente (Kramer 1989, p. 106). Dicha lectura se sostendría sobre una distinción dicotómica radical entre texto y contexto en el que el primero es una expresión nítida del segundo. Ahora bien, ni los contextos históricos son autoevidentes y prístinos a la mirada del historiador ni se limitan a reproducir los cánones históricos de su tiempo. La separación entre dos tiempos, el presente del crítico y el pasado del texto histórico, es inadmisible dadas las peculiaridades de los eventos del pasado siglo. «Es demasiado simple e incluso engañoso creer que se puede plantear una reconstrucción completamente objetiva de lo que ha ocurrido en el pasado que separa el pasado objetivado drásticamente del presente» (LaCapra 2018, p. 35). Además, los procesos subyacentes a la producción de textos son complejos y heterogéneos. En muchos casos son el producto de una interacción constante y conflictiva entre fuerzas unificadoras y contestatarias. Por ello, las prácticas textuales no tienen por qué ejemplificar un canon cultural, pues pueden tender a subvertirlo (LaCapra 1983, p. 187). En este sentido, dada la naturaleza de los acontecimientos que marcan los contextos históricos de los intelectuales del siglo XX-dos guerras mundiales, genocidios y crímenes sin precedentes- LaCapra va a dotar de especial relevancia al impacto emocional y afectivo de la memoria viva de los eventos (2018, p. 83) en los textos históricos, literarios y filosóficos. « [La historia intelectual] puede también explorar la subyacente interacción entre las dimensiones críticas, sintomáticas y menos clarificadas - tal vez indecibles o extrañas - de textos y procesos culturales más generales» (2009, p. 17). Al fin y al cabo, la presencia de estos últimos factores no se explicita únicamente en las representaciones textuales, sino también en sus silencios, en las formas en que un autor interioriza o reprime ciertas experiencias de su tiempo histórico. Aquellas tensiones se revelan en su interpretación de los procesos de escritura de la historia a través de la categoría de trauma. Desde su discusión en torno a los problemas de representación y comprensión de las experiencias «límite» del siglo XX (LaCapra, 1992), se asume la traumatización generada por la violencia como clave hermenéutica para explicar algunos de los textos pertenecientes al canon cultural del pasado siglo - desde Fuga de muerte de Paul Celan a Hiroshima de Margarite Duras, desde La Caida de Albert Camus a Si esto es un hombre de Primo Levy.

Dado el interés por parte de Dominick LaCapra en las humanidades en un sentido amplio, la producción de textos filosóficos será también objeto de estos 
principios metodológicos. El propio LaCapra ha elaborado en sus trabajos sobre el trauma en la escritura una matriz conceptual a la hora de interpretar cómo la filosofía occidental contemporánea ha metabolizado las experiencias masivas de violencia que han marcado a fuego el horizonte histórico de estos autores. Es precisamente a este campo al que circunscribiremos nuestras reflexiones, con especial atención a la interpretación de la ontología de JeanPaul Sartre. Los motivos por los que nos centramos en una de las principales obras del filósofo francés son los siguientes.

En primer lugar, la obra de Jean-Paul Sartre ha generado un enorme interés en el trabajo del crítico norteamericano, desde la redacción de un libro sobre su recorrido intelectual (1978) a la elaboración de varios ensayos sobre su teoría de la novela o la biografía (1983, pp. 184-233). Como defenderemos, una parte importante de la ontología de Jean-Paul Sartre ejemplifica perfectamente las claves hermenéuticas desde las cuales LaCapra interpreta ciertas tendencias en la filosofía occidental contemporánea. La lectura sartreana del ser del hombre como la nihilización del ser del mundo, su interpretación de las relaciones intersubjetivas como irresolublemente conflictivas, y la definición del proyecto existencial humano como una «pasión inútil», instancian perfectamente la lectura que de las tendencias subyacentes a la filosofía occidental realiza LaCapra.

En segundo lugar, al profundizar en factores históricos, sociales y biográficos subyacentes a la ontología de Sartre, la interpretación de LaCapra ofrece claves hermenéuticas para entender su pensamiento que, por sus postulados filosóficos y la complejidad de su tiempo histórico, resultaban opacas al propio pensador francés. «La concepción ultrafenomenológica de la conciencia por parte de Sartre como una espontaneidad vacía le inhibe de plantear el problema de la relación de la conciencia con su propio discurso sobre ello con la tradición y las instituciones en un sentido amplio» (1978, p. 24). Así, al extraer las claves históricas e intelectuales, en la obra de Sartre, LaCapra nos ofrece un marco donde interactúa lo biográfico, lo social y lo filosófico. Esta lectura no simplifica estos elementos hasta el punto de considerar la ontología de Sartre como un mero producto epifenoménico de las tensiones de su tiempo. Tampoco reduce el existencialismo sartreano a una decadente ideología pequeño burguesa. Ni soslaya el rol del diálogo interno de Sartre con otros filósofos. Partiendo de esta base, desde las categorías críticas de LaCapra, reconstruiremos una interpretación donde lo biográfico, lo histórico y lo estrictamente filosófico se entrecruzan constantemente en la obra de Sartre.

Para llevar a la práctica este objetivo, la estructura de este artículo se configura de la siguiente manera. En primer lugar, explicitaremos las claves interpretativas de la historia intelectual de LaCapra. Desde su interior, 
desarrollaremos las distinciones conceptuales mediante las cuales el pensamiento filosófico interactúa con las tendencias que LaCapra glosa bajo el dominio de lo traumático. A partir de ahí realizaremos una lectura de varios pasajes y nociones de El ser y la nada de Sartre, enfatizando aquellos aspectos que relevan la potencialidad de las dinámicas y tensiones anteriormente destacadas por LaCapra. Posteriormente, para dilucidar el rol de lo traumático en la ontología de Sartre, analizaremos el papel de su contexto biográfico e histórico en la configuración de su pensamiento. Finalmente, recogeremos todas las ideas elaborados con el fin de evaluar la potencialidad de las categorías hermenéuticas de LaCapra para abrir nuevos caminos en la interpretación de la ontología sartreana.

\section{Historia INTELECTUAL Y TRAUMA EN DOMINICK LACAPRA}

La crítica de LaCapra al reduccionismo que opera en el contextualismo historicista le conduce a enfatizar la compleja genealogía a través de la cual los textos son producidos, canonizados y archivados. Dadas las características del siglo XX y el influjo todavía vivo de aquellos acontecimientos, las emociones, las represiones y los silencios que esconden los textos escritos durante aquel horizonte histórico suponen un exceso que dificulta su interpretación.

Los archivos en sí mismos, en lugar de ser considerados como el fundamento de la certeza en la historia [...] pueden entenderse de forma más crítica como un sistema de inscripciones cuyos contenidos y procesos pueden, en mayor o menor medida, realizarse a través de fuerzas, incluyendo fuerzas afectivas e ideológicas [...] con sus supresiones, represiones, e inclusiones, exclusiones y distorsiones selectivas (2018, p. 94)

En este sentido, LaCapra recupera las principales tesis de Mal de Archivo de Derrida (1997) para abordar la interpretación de textos legados por la tradición - histórica, literaria o filosófica - como producto de un intrincado conjunto de fuerzas que incluyen la memoria viva y la injerencia del poder vigente en el contexto en el que fueron producidos. La recuperación por parte de LaCapra de la obra en la que el filósofo argelino dialoga con Freud apunta a su adopción de la herencia de dos tradiciones de pensamiento contemporáneo: la deconstrucción y el psicoanálisis. Frente a la temporalidad lineal que articula el contextualismo historicista ambas corrientes habilitan la comprensión de otra forma de articulación del tiempo. «Tanto en Derrida como en Freud [...] la temporalidad es repensada en términos de desplazamiento o repetición con cambios, en algunas ocasiones cambios drásticos o traumáticos» (2018, p. 55). Respecto a la deconstrucción, LaCapra adoptará fundamentalmente la superación y disolución de las oposiciones binarias o dicotomías definitivas en el análisis de textos - entre el «adentro» y el «afuera» del texto, entre pasado 
y presente, entre texto y contexto (Norrir 1982). Del psicoanálisis extraerá la aplicación de las nociones fundamentales del diagnóstico psicopatológico al análisis de los textos históricos; uno de los aspectos más polémicos de su propuesta.

Los conceptos básicos del psicoanálisis son pertinentes - y problemáticos - en formas comparativas respecto a individuos y colectivos. (Esta afirmación se aplica a los conceptos $[\ldots]$ : transferencia, trauma, repetición y elaboración). En otras palabras, estas nociones menoscaban la oposición clásica entre el individuo y la colectividad, pueden ayudarnos a repensar esta oposición y son en diferentes grados aplicables de formas individuales o colectivas, dependiendo de los contextos y las situaciones (2004, p. 74).

La noción de transferencia capta la co-implicación emocional entre el intérprete y los eventos y textos a investigar, desdibujando las fronteras entre pasado y presente. Es precisamente esta separación la que tiende a colapsar dado el influjo de las fuerzas históricas que LaCapra enmarca bajo la noción de trauma. Dado el acaecimiento de experiencias de violencia hiperbólicas sin precedentes a lo largo del siglo XX, la teoría crítica y los estudios literarios han recurrido a la noción de trauma como índice de la imposibilidad de representar, narrar y dar sentido a esas experiencias. En su trabajo primigenio sobre la literatura y el trauma, Cathy Caruth mantiene que «el trauma pone en cuestión los modos básicos de referencialidad» (1996, p. 14) y exige del recurso a técnicas literarias alternativas para reflejar la insuficiencia de las palabras y las narrativas a la hora de representar esos eventos. Por ello, a través del análisis de la obra de autores como Kafka, Celan, Beckett... Caruth defiende que la literatura es el espacio privilegiado para captar y reflejar la presencia del desgarro traumático. Frente a la relación privilegiada, exclusiva y excluyente, entre trauma y literatura, LaCapra reivindica la necesidad de ampliar los campos semánticos asociados al trauma para abarcar así otras disciplinas como la historiografía y la filosofía: «uno puede incluso afirmar que plantear tales cuestiones es parte de las formas a través de las cuales estos textos son perturbadores [...]. Uno puede abordar cuestiones similares en filosofía, particularmente en filosofía cercana a, o en un diálogo desafiante con, la literatura» (2014, p. 189). Ahora bien, ello no obsta, en ningún caso, para desdibujar completamente las fronteras entre filosofía y literatura. Dominick LaCapra es especialmente cuidadoso a la hora de establecer distinciones teóricas en relación al influjo de las experiencias traumáticas en los diferentes procesos de escritura. Prueba de ello es su separación conceptual entre dos formas de entender el trauma. El exceso irrepresentable asociado al trauma se articula de diferente manera en función de si tales desafíos a la representación son considerados o no consecuencias de eventos históricos concretos. Dicha 
separación se traduce, a su vez, en la distinción entre dos categorías a la hora de lidiar con las secuelas de la experiencia traumática: la ausencia y la pérdida.

La pérdida refiere a la «falta»o «carencia» provocadas por una experiencia concreta que es posible contextualizar históricamente y cuya intensidad es posible gradar. «Las pérdidas son específicas e implican eventos particulares, como la muerte de seres queridos a un nivel personal, o en una escala amplia, las pérdidas provocadas por el apartheid o por el Holocausto en sus efectos en judíos y otras víctimas del genocidio nazi» (2014, p. 49). La ausencia, en cambio, si sitúa en un nivel transhistórico. Remite a la falta de un estado de plenitud que, aunque postulado en un pasado lejano indefinido, no se puede situar en un eje diacrónico específico. Los discursos en torno a la ausencia refieren a una condición ontológica o antropológica faltante. Es, por tanto, un trauma ahistórico, originario y fundacional en la vida de los individuos y los grupos; ya sean los resortes de estos discursos teológicos, filosóficos y políticos. Dicha herida traumática condiciona toda la historia del grupo humano que leerá su propia proyección diacrónica desde la aspiración al retorno a aquel estado primigenio de plenitud que, por su propia condición transhistórica, se revela ilusoria. «La ausencia aparece en todas las sociedades o culturas [...] uno no puede perder lo que nunca tuvo. Respecto a la crítica de los fundamentos, uno puede argumentar que la ausencia (no la pérdida) se aplica a los fundamentos últimos en general, especialmente a los fundamentos metafísicos» (Ibid, p. 50).

El énfasis del crítico norteamericano en la separación entre estos dos niveles tiene como principal objetivo criticar la confusión y el desdibujamiento ente ambos. El mayor peligro, desde su perspectiva, a la hora de lidiar con una experiencia histórica traumática radica en introducirla en un discurso abstracto que la representa como una ausencia. De esa forma, el acaecimiento de procesos colectivos de violencia masiva se deshistoriza, se convierte en algo ahistórico y fundacional. Ningún hecho histórico- pérdida - puede dar lugar a un desgarramiento en los fundamentos a nivel antropológico u ontológico ausencia - de un grupo humano. ${ }^{1}$ Ya que, en ese caso «se subsume lo histórico en una historia transhistórica, melancólica, y extremadamente luctuosa de catástrofe infinita» (2016, p. 203). El trauma se prefigura como un evento fundacional cuyas secuelas constituyen las condiciones con las que debe lidiar un grupo humano a lo largo de su propia historia. De ahí que LaCapra lo denomine como un trauma estructural. El trauma estructural o transhistórico remite a una brecha o negación inherente a la humanidad que debe lidiar, a

1 LaCapra moviliza este marco conceptual para cuestionar las reflexiones filosóficas de autores como Giorgio Agamben (LaCapra 2004, pp. 144-194) y Slavoj Zizek (LaCapra 2013, pp. 203-224). 
lo largo de su historia, con los efectos de esa sutura originaria. Es más, su propia historia será identificada con el proceso a través del cual lidia con esa herida. Precisamente, LaCapra localiza una tendencia a representar la historia y los fundamentos ontológicos del ser humano desde la referencia a un trauma estructural originario en el interior de la tradición filosófica occidental. A través de una lectura tan heterogénea que incluye el psicoanálisis, la fenomenología, el existencialismo, el materialismo... detecta diversas formas de conceptualizar esa ausencia fundacional.

Se puede reconocer, con matices, de un modo explícitamente especulativo y al menos en importantes dimensiones de la llamada tradición occidental, la pertinencia de algo así como un trauma transhistórico, o brecha, escisión, vacío, o ausencia que a lo largo del tiempo se ha conceptualizado de diversos modos, incluyendo la caída y el pecado original [...], el paso de la natura a la cultura (con la caída, posiblemente valorizada pero traumatizante, del instinto), la edipización con la ruptura de la relación pre-edípica con la madre, la irrupción en el lenguaje o significación (a menudo considerada traumática o forzada), y la relación aniquiladora del para-sí con el en-sí (2016, p. 205).

La ontología sartreana aparece como última parada en este recorrido exegético donde se prefigura la historia humana desde el vacío o desgarramiento identificado con el trauma estructural. Es cierto que LaCapra no realiza un análisis sistemático respecto a cómo la fenomenología de Sartre reproduce estas tendencias. Ya que sus textos dedicados al filósofo francés atienden más a aspectos literarios o estilísticos de su obra. Precisamente, este es el vacío que pretenden rellenar las siguientes líneas: analizar algunas de las categorías más importantes de la ontología sartreana movilizando las nociones ofrecidas por la crítica de LaCapra. Este estudio no tratará de esclarecer únicamente la relevancia del trauma estructural a la hora de interpretar la temprana obra filosófica de Sartre. También evaluará en qué medida se explicita bajo algunos aspectos y recorridos de la ontología del filósofo francés el citado desdibujamiento entre lo histórico y lo transhistórico. Al fin y al cabo, desde la perspectiva del crítico norteamericano, la distinción entre ausencia y pérdida no constituye un binomio o una dicotomía excluyente. Sus solapamientos en algunos contextos son inevitables. La distinción entre ausencia y pérdida «no se puede construir como un simple binario porque las dos son interacciones de formas complejas en cada situación concreta, y existe una enorme tentación de confundir una en la otra, especialmente en situaciones postraumáticas o períodos experimentados en términos de crisis» (2014, p. 48).Vivir períodos de inestabilidad, crisis o incertidumbre puede favorecer la proyección de lecturas de la historia en términos de trauma estructural. Es precisamente esta tensión la que vamos a detectar en algunas partes de la ontología de Sartre. 
Por este motivo, nuestro estudio tendrá una doble vertiente. En primer lugar, analizaremos las tesis de Sartre haciendo énfasis en aquellos elementos de su ontología que instancia aquello que LaCapra denomina como un trauma estructural. En segundo lugar, retomaremos varios estudios biográficos e históricos del contexto sartreano para especificar en qué medida aquellos acontecimientos pudieron contribuir a la elaboración de dichas tesis.

\section{NIHILIZACIÓN Y LIBERTAD ABSOLUTA EN EL EL SER Y LA NADA}

Dada la imbricación entre lo literario y filosófico en la obra de Jean Paul Sartre, la expresión más clara de la aprehensión de una experiencia de desgarramiento ontológico incontextualizable, la encontramos en la escena más conocida de su novela La Náusea; publicada cinco años antes de El ser y la nada (1943). «Lo esencial es la contingencia. [...] por definición, la existencia no es la necesidad. Existir es estar ahí, simplemente. [...] Es lo absoluto, en consecuencia, la gratuidad perfecta, todo es gratuito» $(2008$, p.106)

La comprensión de la radical contingencia de la existencia humana deriva de la asunción respecto a la alteridad y fisura entre el ser del mundo y la existencia humana. A través de un conjunto de descripciones que prefiguran la posterior distinción entre el ser en-sí y el ser para-sí (LaCapra 1978, p. 111). Esta distinción constituirá la clave de bóveda de la posterior ontología sartreana.

Las premisas de El ser y la nada pueden interpretarse como el inicio de un diálogo con parte de la tradición filosófica que le precede. Al fin y al cabo, El ser y la nada mantiene una deuda innegable con el pensamiento de Hegel, Husserl y, especialmente, Heidegger. Pese a que, como recuerda Ethan Kleinberg (2006, p. 148) finalmente sus tesis no concuerden con ninguno de ellos. Precisamente en los trabajos pioneros de Sartre en los que dialoga con las categorías de Husserl - sobre la intencionalidad, la imaginación o la emoción - se encuentra el germen de su posterior ontología fenomenológica. Tal y como es posible apreciar en La trascendencia del ego (2003) Sartre recupera la analítica de la intencionalidad husserliana en tanto que ofrece la posibilidad de un campo especulativo trascendental impersonal que no tiene un objeto cognoscente reflexivo sino un correlato múltiple irreflexivo. Ahora bien, al contrario que en el caso de Husserl, este espacio no es el producto de una epoje trascendental, ni de un proceso reflexivo, sino más bien de «una angustia que se nos impone y que no podemos evitar» ${ }^{2}$ (2003: 66). Por este motivo, Sartre rechazará la metodología de la analítica trascendental de Husserl y la subjetividad reflexiva que a aquella la acompaña, a la que considera un residuo del esencialismo. «Poner delante de sí la interioridad es darle peso

2 Agradezco al revisor del artículo esta anotación conceptual y exegética. 
y hacerla objeto» (Ibid: 60). Desde su perspectiva, aquella no es más que el producto de la reflexión de la conciencia sobre su propia actividad. Pero de forma previa a su actividad cognoscente, la conciencia existe y está lanzada al mundo, «es movimiento centrífugo desde la excentricidad primordial del existente» (Moreno 2000, p. 96).

En este sentido, la ontología de Sartre es el producto de la radicalización de la fenomenología. Prueba de ello es que el punto de partida de El ser y la nada no es sino el denominado monismo del fenómeno. «El pensamiento moderno ha realizado un progreso considerable al reducir el existente a la serie de apariciones que lo manifiesta» (Sartre 2013, p. 11). Ahora bien, prosigue la argumentación de Sartre, debe haber un ser del fenómeno al que se dirige la conciencia, más allá del propio fenómeno. En caso contrario, la conciencia no sería intencional pues no saldría de sí ya que no estaría dirigida a nada fuera de sí mismo (Levy 2001, p. 134). «El ser del fenómeno, aunque coextensivo al fenómeno, debe escapar a la condición fenoménica [...] desborda y funda el conocimiento que de él se tiene» (Sartre 2013, p. 17). Hay, por tanto, una irreductibilidad ontológica entre el ser del mundo y el de la conciencia que en líneas posteriores adquiere la forma hegeliana de una separación entre en ser en-sí y el ser para-sí. La definición antagónica de ambas regiones ontológicas es la fuente desde la que se prefigura a la subjetividad humana como un desgarramiento ontológico estructural.

Desde el punto de vista de Sartre, el ser en-sí es idéntico consigo mismo, es pura plenitud. Se define de forma tautológica: el ser en-sí es lo que es, pura identidad plena contigo misma. «El ser en-sí no tiene un dentro que se oponga a un fuera y que sea análogo a un juicio, a una ley, a una conciencia de sí [...] es macizo. [Es] una síntesis [...] de sí consigo mismo» (Ibid, p. 37). Frente a la plenitud ontológica del mundo, la conciencia introduce la negación o la pregunta; es decir, una distancia respecto a sí. Y, por tanto, sutura la identidad del ser en-sí. «La característica de la conciencia, al contrario, está en una descompresión de ser. Es imposible [...] definirla como coincidencia consigo misma. De esta mesa puedo decir que es pura y simplemente esta mesa. Pero de mi creencia, no puedo limitarme a decir que es creencia: mi creencia es conciencia de creencia» (Ibid, p. 124). La conciencia, el ser para-sí se caracteriza por una carencia ontológica; por no ser idéntico a sí mismo. El parasí difiere del en-sí en tanto que, en sentido escrito, no es. «Es obligación para el para-sí no existir jamás sino en la forma de un en-otra-parte con respecto a sí mismo» (Ibid, p. 129). La conciencia es la fisura ontológica que introduce la Nada en el ser. «La realidad humana es algo así como un gusano que se enrolla en el corazón del ser» (Crowell, p. 207). El hombre es la nada que introduce un proceso de nihilización en el ser del mundo. En la obra de Sartre existe una conexión esencial entre la conciencia y la nada (Richmond 2014 p. 94). «El 
hombre se presenta [...] como un ser que hace surgir y desplegarse la Nada en el mundo, en tanto que, con ese fin, se afecta a sí mismo de no-ser» (Sartre, 2013, p. 67). Al contrario que el ser en-sí, el para-sí no es, no es definible, es pura contingencia en un constante proceso de hacerse a sí mismo; se realiza como no siendo. Tal y como lo describe Mark Poster, la caracterización que ofrece Sartre del ser para-sí actualiza la «conciencia desdichada hegeliana» en la que el hombre sufre de una escisión final entre sí mismo y el mundo (1973, p. 55). Ahora bien, esta ruptura no es final, sino originaria. Ya que está en la estructura del ser del hombre consistente, fundamentalmente, en su ausencia de ser. Esa ausencia de identidad consigo mismo es la fuente del deseo y la acción. No es difícil apreciar en qué media estas tesis ejemplifican los discursos filosóficos que LaCapra asociaba al «trauma estructural» ${ }^{3}$. El ser del hombre es una brecha ontológica, una sutura no contextualizable que marca los presupuestos de su acción y de estar en el mundo. Al carecer de sustancia alguna, no tiene asidero respecto al que justificar su acción más allá de sí mismo. El ser del hombre se identifica con una carencia que justifica ontológicamente su libertad absoluta.

Es preciso explorar otro aspecto de su ontología que se puede prefigurar desde la referencia a una brecha originaria. El rol que juega el trauma estructural en El ser y la nada no se limita al origen mismo de la conciencia. Ya que subyace también a la estructura de las relaciones intersubjetivas. Para dar cuenta de la complejidad de lo humano Sartre introduce un tercer elemento en su ontología: el ser-para-otro. Dadas sus premisas, el otro no puede sino irrumpir violentamente la relación del para-sí con el mundo. Si para Sartre el para-sí es lo que no es, puro proyecto que interactúa con el mundo y despliega en aquel sus posibilidades, la aparición de una alteridad genera una brecha en ese campo de experiencia. El otro no es como el resto del mundo, un objeto de mi campo de percepción. Hay un polo subjetivo más

3 Es preciso reconocer, como especificaremos más adelante, las limitaciones conceptuales y exegéticas del potencial heurístico de la categoría de «trauma estructural» ofrecida por Dominick LaCapra a la totalidad de la ontología sartreana. La dinámica que captar esta categoría - la postulación de una brecha ontológica fundacional que desencadena comportamientos dirigidos a la reversión suturación de esa brecha originaria - no se aplica a toda su ontología ni capta todo comportamiento humano posible ante esas premisas, sino más bien al comportamiento de mala fe que configura la actitud irreflexiva ante la cual el hombre reacciona a estas heridas ontológicas. El deseo del ser-para-sí a la hora de ser en-sí para recuperar su plenitud ontológica no agota toda reacción posible, desde la filosofía sartreana, ante esta condición ontológica. Más bien, refiere al comportamiento propio de la mala fe y la actitud impura que, ante la angustia generada por la absoluta libertad del para-sí, reniega y rehúye de la misma a través de la búsqueda de asideros mediante los cuales justificar su acción y suturar la brecha ontológica originaria. Agradezco profundamente al revisor del artículo esta anotación. 
allá de ello que yo no puede encontrar en la experiencia fenoménica; «en la medida en que el otro es ausencia, escapa mi naturaleza» (Sartre 2013, p. 233). Ahora bien, el otro tiene su campo de percepción, en que yo aparezco como mero objeto. «El prójimo [...] se presenta, en cierto sentido, como la negación radical de mi experiencia, ya que es aquel para quien soy no sujeto sino objeto» (Ibid). La primera relación con el otro se da a través de su mirada. Aquella plantea mi posible objetivación. Al ser visto por el otro como objeto, como una cosa, se niega la libertad y pura posibilidad que soy. «Soy aquel que el otro experimenta como objeto» (Overgaard 2013). Por tanto, la aparición de la intersubjetividad amenaza al proyecto existencial del para-sí. En su análisis sobre la obra de Sartre, Fredric Jameson define el shock, la alienación, que genera en el para-sí la aparición del otro como un trauma. «La mirada, el trauma de la existencia del otro - esa contingente y pese a ello irreparable experiencia que me confiere un «afuera» y una objetividad, al mismo tiempo convierte todas mis acciones en el mundo en un conflicto» (1974, p. 300). Así, la intersubjetividad en sus diferentes formas aparece lastrada por la sombra de este trauma producido por la aparición del otro en la ontología sartreana. Dada esta situación, la reacción del sí mismo ante la posibilidad de devenir simple objeto para-otro es, a su vez, la de proyectar su mirada sobre él, para recuperar la situación inicial del para-sí frente al mundo. Bajo este prisma, las relaciones entre los grupos humanos ejemplifican la lucha hegeliana por el reconocimiento en el interior de una lógica intersubjetiva necesariamente conflictiva (Moreno 2000, p. 108). La expresión más clara de esta irresoluble tensión la encontramos nuevamente en un trabajo filosófico de Sartre que, en boca de Garcín en A puerta cerrada concluye «el infierno son los otros» (2005, p. 135).

La fracasada relación con el otro no es más que un caso fallido en el proyecto existencial del para-sí que se articula bajo el desgarramiento ontológico que da origen a la conciencia. Es aquí donde las categorías de LaCapra muestran su virtualidad. Al fin y al cabo, ante la postulación de un trauma estructural en el origen de la conciencia y la intersubjetividad se articula un comportamiento de huida y mala fe que Sartre describe como dirigido a suturar esa brecha ontológica y de la recuperación de la plenitud originaria. Así, la noción de trauma estructural de Dominick LaCarpa revela toda su potencialidad heurística a la hora de dar cuenta de la noción de reflexión impura o cómplice. Es decir, la ontología de Sartre no instancia el trauma estructural diagnosticado por LaCapra únicamente en tanto que define al hombre originariamente como carencia de ser. También y más específicamente en la medida en que, bajo la sombra de ese trauma estructural, de esa sutura ontológica, es descrita una reacción común de huída ante la condición «diaspórica» del para-sí a través de la cual el sujeto reniega su libertad constitutiva y trata de revertir esa herida y a 
recobrar la plenitud originaria. La brecha ontológica deriva, en este caso, en la lectura del proyecto vital como una restauración de una ausencia primigenia. «[El sujeto sartreano] es trágicamente libre, sin fundamento, motivado por el deseo y las posibilidades que no puede realizar [...] La conciencia nunca está completamente consigo misma, consiste en su propia ausencia de ser [...] y persigue un proyecto condenado de auto-coincidencia» (Davis 2007, p. 45).

Al final de su recorrido en torno a los deseos y acciones del para-sí que instancian la actitud de mala fe, Sartre mantiene que aquel, en tanto contingente y carente de ser, traza de realizarse a sí mismo a través de su proyecto existencial. Intenta encontrar, en su propio proyecto, la razón de sí mismo; rasgo característico del ser en-sí. Dicha tentativa no hace sino remitir a la región ontológica de cuya nihilización deriva el propio hombre. Su proyecto existencial se dirige, en última instancia, a la superación del trauma estructural, alcanzando el estatuto de ser en-sí-para-sí:

en tanto que conciencia, quiere tener la impermeabilidad y la densidad infinita del en-sí; en tanto que nihilización del en-sí [...] quiere ser su propio fundamento. Por eso el posible es proyectado en general como aquello que falta al para-sí para convertirse en en-sí-para-sí; y el valor fundamental que preside a este proyecto es [...] el ideal de una conciencia que sea fundamento de su propio ser-en-sí [..] A este ideal puede llamarse Dios (2013, p. 764).

Dios es el horizonte último del sujeto sartreano. A través de la búsqueda de un estado de completitud encarnado en el ser en-sí-para-sí la ontología de Sartre termina articulando una «nostalgia por el ser perdido» (Jay 1984, p. 353). Este proyecto está condenado de antemano por la propia estructura ontológica del para sí. La «eterna melancolía» que LaCapra atribuye a la tradición filosófica sobre el trauma estructural tendría su instancia en la descripción sartreana del hombre como «pasión inútil». Ya que es imposible suturar la herida ontológica originaria, pero a la vez no puede dejar de proyectar ese deseo de plenitud. En definitiva, el rol que Dios juega en la ontología de Sarte, el ser en-sí-para-sí, como telos de la acción humana y recuperación de esa estructura ontológica previa a un desgarramiento originario, termina de vincular su pensamiento con la lectura de LaCapra en torno al «trauma estructural». Al fin y al cabo, el efecto último de esta estructura ontológica sobre aquel que en la historia actúa desde la mala fe no es sino el deseo de redención o totalidad o, en palabras de Sartre, «el deseo de ser un ser en-sí-para-sí o Dios» (LaCapra 2014, p. 77). 
IV. Cautiverio, Libertad y trauma en la Francia ocupada de Jean-Paul SARTRE

Para evaluar la virtualidad de la noción de trauma estructural como herramienta hermenéutica en la interpretación de la ontología de Sartre, es preciso acudir al contexto histórico del autor. Al fin y al cabo, desde la perspectiva de LaCapra, la tendencia a construir un sistema filosófico en torno a una herida originaria se acentúa en contextos de crisis, tras experiencias de violencia e incertidumbre. Es decir, el acaecimiento de experiencias históricas traumáticas y la tendencia a hiperbolizar sus efectos conducen a la ya citada confusión entre la ausencia y la pérdida que motivan la proyección de un «trauma estructural». Debemos explorar en qué medida el contexto de violencia, incertidumbre y cautiverio, desde el que se redacta El ser y la nada ha podido contribuir a la elaboración de las tesis que han centrado nuestro acercamiento a su ontología. Debemos detenernos en el contexto biográfico e histórico de los años cuarenta, en el interior de un conflicto bélico mundial y de una Francia ocupada por los nazis. Esta investigación nos permitirá profundizar en la cuestión respecto a si, detrás de la obra de Sartre, aquellas circunstancias de incertidumbre y privación de libertad de la sociedad francesa pueden considerarse como una experiencia traumática, en el sentido en el que las interpreta LaCapra. Dado su esquema interpretativo, aquellas podrían haber coadyuvado a la elaboración de tesis en torno a un «trauma estructural». $\mathrm{Al}$ acentuar la imbricación entre lo biográfico, lo histórico y lo filosófico nos hacemos eco de la lectura que sobre este período de la obra de Sartre propone en su biografía Annie Coen-Solat: «Su teoría de la libertad la elabora en la abstracción filosófica, pero se basa en sus condiciones históricas» (2005, p. 251).

En relación a los vínculos entre la vida de Sartre y su pensamiento, son varios los intérpretes que han aludido a la infancia del filósofo francés a la hora de explicar el rol central y la radicalidad de la libertad en su obra. La temprana orfandad de padre y la carencia de una voz de autoridad, constituye, sin duda, un elemento central de su biografía (Sartre 1981, 32). Como él mismo plantea retomando la terminología psicoanalítica: «No tengo superego» (Ibid. p. 19). La pérdida temprana del progenitor que, tradicionalmente, es el encargado de imponer deberes y normas, abrió al filósofo francés desde su infancia un enorme abanico de posibilidades. En su estudio sobre Las palabras, LaCapra establece esta relación en los siguientes términos: «Ausente como autoridad paterna, el padre jugó un rol similar al del Dios perdido [...] La muerte del padre está relacionada con la noción de libertad en su forma pura y total» (1978, p. 187). 
No obstante, el acontecimiento que construye el trasfondo desde el que Sartre escribe El ser y la nada resulta antagónico respecto a su contexto familiar, en términos de libertad. Como plantea Mark Poster, resulta paradójico e irónico que Sartre presentara su doctrina sobre la liberad radical durante el período de ocupación donde los franceses eran menos libres (1973, p. 78). A partir de este contraste, varios intérpretes han considerado la obra temprana de Sartre como la expresión de una filosofía pequeño-burguesa, idealista, completamente ajena a las circunstancias materiales (Aronson, 1973). Su propia participación en el conflicto refuerza la imagen de un pensador enajenado respecto a su experiencia histórica. Tanto en la retaguardia como en su cautiverio, Sartre se comportaba como un personaje poco interesado en el conflicto de su tiempo que dedicaba buena parte de su tiempo a la escritura filosófica y literaria. Este aparente extrañamiento de sus circunstancias históricas llegó a sus conclusiones más radicales en su afirmación según la cual nunca fue más libre que en los campos de detención alemanes (Sartre 1960, p. 11). Además, una vez liberado de aquel campo de detención, la experiencia del filósofo en la Francia ocupada fue relativamente plácida; sin grandes sobresaltos ni vivencias explícitamente dolorosas. «No ha de olvidarse que la ocupación fue cotidiana» (Ibid, p. 16).

No obstante, esta lectura inicial no debe hacernos minusvalorar el impacto de la guerra en el pensador francés. Como él mismo manifestaba, la guerra dividió su vida en dos (Ibid, p. 19). Ahora bien, el conflicto histórico no se manifestó directamente en su experiencia. Ya que él nunca llegó a combatir en el frente. Se parecía más bien a lo que Cohen-Solal definió como una «guerra a lo Kafka» (2005, p. 213); un conflicto extraño que no llegó a vivir en sus consecuencias pero que siempre le acechaba. Ya fuera desde la distancia de la reserva militar o el cautiverio. De esta forma difusa, la guerra generó una ruptura en su experiencia que incubó muchas de las posteriores tendencias de su pensamiento (Idid, p. 251).

Había un enemigo - y el más aborrecible - pero no tenía rostro. O por lo menos, de los que vivieron pocos regresaron para describirlo. Lo compararía de buen grado con un pulpo que se apoderaba en la sombra de nuestros mejores hombres y los hacía desparecer. Parecía que se produjeran en torno a nosotros engullimientos silenciosos (1960, p. 19).

Es bien cierto que en ningún momento Sartre refirió en El ser y la nada al conflicto que estaba viviendo. Todos los ejemplos sobre los que se elaboran sus argumentos son recuperados de experiencias cotidianas relativamente 
anodinas ${ }^{4}$. Ahora bien, como plantea Colin Davis, tales referencias hubieran sido imposibles dada la censura por la que tenía que pasar su obra en la Francia ocupada por los nazis $(2003)^{5}$. En este sentido, hay varios elementos de su ontología fenomenológica que se entienden mejor a través del influjo de la Segunda Guerra Mundial en su situación histórica. En primera instancia, su teoría de la libertad radical no deja de tener un significado especial en el contexto de la Francia ocupada. Desde la perspectiva de la ontología de Sartre, pese a los chantajes o las penurias de las condiciones históricas, el individuo es igualmente libre para elegir entre la colaboración con el fascismo y la resistencia. La experiencia de la ocupación confronta a Sartre con la última realidad humana. Frente a todas las justificaciones y excusas a través de las circunstancias materiales - que glosa como «mala fe» - el filósofo francés mantiene su apuesta por la libertad radical.

En segundo lugar, el conflicto bélico condiciona sin duda alguna el desarrollo de su teoría sobre la intersubjetividad. Sartre vivió la guerra indirectamente a través de las noticias, la llamada a filas o el cautiverio, no directamente en el frente. Desde su perspectiva, la guerra está en todas partes y a su vez en ninguna. «El horror [...] constituía a la vez la trama de nuestras conciencias y el sentido del mundo [...] cuando estábamos sumergidos en el horror, se nos había hecho tan familiar que a veces lo considerábamos la tonalidad natural de nuestros estados de ánimo» (Sartre 1960, p. 19). La sociabilidad humana se experimenta, en este contexto, en términos de violencia y constante amenaza. La dialéctica de la mirada y la interpretación de la acción intersubjetiva como conflicto en lugar de colaboración, está sin duda atravesada por este tipo de tensiones históricas. Nos hacemos eco de la interpretación de Fredric Jameson según la cual «la experiencia básica de este tipo de alienación para el propio Sartre parece haber sido el estallido de la Segunda Guerra Mundial, en la que millones de libertades parecían cancelarse las unas a las otras en total desamparo» $(1974$, p. 247).

La cuestión que surge en este punto es si el influjo de estas experiencias en su obra filosófica justifica el recurso a la noción de trauma histórico en el contexto biográfico durante el que Sartre escribió El ser y la nada. Es decir, si este tipo de vivencias puede ayudarnos a entender su elaboración de un trauma estructural en el origen de la subjetividad humana y la sociabilidad y en la elaboración de las raíces ontológicas subyacentes a los comportamientos

4 Esta cotidianidad ha sido considerada como unas de las virtudes de filosofía. Como recoge Simon de Beauvoir «Ves, mi pequeño camarada, si eres husserliano puedes hablar de este cóctel y hacer filosofía» (1961, p. 141).

5 Merece la pena reseñar que en la conferencia que dio lugar al Existencialismo es un humanismo(2004), donde, ya después del fin la de la guerra, trata de discutir y defender de forma divulgativa las tesis de El Ser y la Nada, si aparecen ejemplos de esta naturaleza. 
de mala fe. Aquella constituiría una instancia del desdibujamiento entre lo histórico y lo transhistórico que diagnosticaba LaCapra.

En primera instancia, es preciso reconocer que los textos de Sartre durante el período de ocupación - tanto literarios como filosóficos - no articulan una experiencia traumática en el sentido en que lo hacen aquellos ensayos - como en Celan, Becket o Blanchot - que han interesado a la teoría literaria sobre el trauma desde sus inicios. En sus textos no hay, como tales, represiones, silencios o recursos estilísticos que expliciten la irrepresentabilidad de una experiencia de estas características. «No incluyen ninguno de los signos estructurales, semánticos o gramaticales que los caractericen como textos trauma» (Davis 2018, p. 55). La guerra estaba ausente de su campo de experiencia. Pero a su vez marcaba opresivamente su contexto histórico. Prueba de ello es que el propio Sartre aborda el problema de la comunicación de la experiencia de vivir en Francia durante la ocupación.

Volvía del cautiverio y me interrogaban acerca de la vida de los prisioneros: ¿cómo hacer sentir la atmósfera de los campos de concentración a quienes no habían vivido en ellos? [...] ¿cómo dar una idea cabal de lo que fue la ocupación a los habitantes de los países que permanecieron libres? Hay un abismo entre nosotros que las palabras no podrían colmar (1960, p. 14).

En este sentido, no es posible soslayar que la incertidumbre y el peso opresivo de la guerra en su horizonte histórico han marcado su obra y el pensamiento durante aquellos años. Pese a que los argumentos mediante los que discurre sus tesis ontológicas tengan peso por sí mismo, no pueden abstraerse de las experiencias y el clima histórico de incertidumbre que las generó. Pese a no vivir en su carne ni expresar directamente en sus textos vivencias traumáticas, experiencias de esta naturaleza atraviesan su pensamiento en su totalidad y resultan indispensables para interpretar sus textos filosóficos. «Los escritos de guerra de Sartre [...] y sus trabajos de postguerra que refieren a la guerra están atravesados por y describen tiempos traumáticos» (Davis 2018, p. 57). Sin la incertidumbre y el desasosiego que aquellas generaron no pueden entenderse algunas de las tesis defendidas en El ser y la nada.

\section{CONCLUSiOnes}

A finales de la década de los sesenta, Jean-Paul Sartre concede una entrevista donde reflexiona, entre otras cuestiones, sobre el valor de su primera gran obra en los siguientes términos. Pese a reconocer que su posterior Crítica de la Razón Dialéctica hereda elementos de aquel trabajo, esta constituye a la vez una conversión de un proyecto original en el que se había lanzado a sí mismo a los brazos de la ansiedad antes la nada (1960, p. 34). Dicha tensión, parece reconocer el propio Sartre en esta entrevista, se mueve en el interior de las 
dinámicas entre su experiencia exterior y las circunstancias de su tiempo. « El ser y la nada trazó una experiencia interior, sin ninguna coordinación con la experiencia exterior de un intelectual pequeño burgués, que se convirtió en catástrofe histórica en un momento determinado. Por eso escribí El ser y la nada después de la derrota de Francia» (Ibid, p. 35). Su justificación ontológica de la libertad absoluta articula una potencialidad para trascender las circunstancias, para rebasarlas y redefinirse. Cualquiera que sea la situación en que viva el hombre, puede elegir ser una cosa u otra. Proyecta una tendencia a desarraigarse, a través de su acción, sus propias circunstancias históricas. A su vez, este deseo de trascendencia que se expresa en esta afirmación de la libertad incondicional no se puede desligar, como reconoce, de su propia experiencia histórica.

Lo que el drama de la guerra me aportó, al igual que lo hizo con todos aquellos que participaron en ella, fue la experiencia del heroísmo. No el mío, por supuesto [...] Sino la del militar en la resistencia que fue capturado y torturado, se convirtió en un mito para nosotros. Aquellos militantes existían, pero representaban un mito para nosotros también. ¿Seríamos capaces de resistir a la tortura de la misma manera? (Ibid, p. 34).

Como es posible apreciar, la imbricación entre lo histórico, lo biográfico, lo filosófico y el deseo metafísico de «trascendencia en la inmanencia» subyacen al complejo entramado de argumentos que componen El ser y la nada. Determinar qué rol juega cada uno de estos elementos heterogéneos en la ontología fenomenológica sartreana es una tarea todavía pendiente en la exégesis de su obra. En este sentido, como hemos tratado de demostrar, la recuperación de las nociones de LaCapra aporta luz sobre algunas de estas tensiones. El recurso a la categoría de trauma con especial atención a la distinción conceptual no dicotómica entre pérdida y ausencia, ilumina aspectos inexplorados del pensamiento de Sartre. La noción de trauma histórico arroja luz respecto a la metabolización de las tumultuosas circunstancias históricas en su obra filosófica. La de trauma estructural, a su vez, permite enlazar parte de su ontología con la tradición filosófica a la que pertenece, en una forma que resulta inaccesible al propio Sartre. «Sartre [...] presenta la búsqueda del ser en-soi-pour-soi como algo ontológicamente dado en lugar de cómo un proyecto situado en la tradición metafísica occidental» (1978, p. 128). Además, la interpretación según la cual el trauma histórico puede coadyuvar a la confusión entre lo histórico y lo transhistórico, permite dar cuenta de cómo Sartre metabolizó las experiencias de su tiempo en su propio trabajo filosófico más abstracto

A partir de la historia intelectual de Dominick LaCapra es posible iluminar estas conexiones y dependencias que, en algunos casos, resultaban opacas al 
propio filósofo francés. Como hemos analizado, desde la lectura de LaCapra, «en la aprehensión de la libertad a veces exorbitante de Sartre, uno cuenta una paradójica expresiónde deseo metafísico» (1983, p. 233). Dicha inclinación remite al deseo de plenitud ontológica postulado por Sartre; aquel que instancia una comprensión del ser del hombre desde el trauma estructural que le alinea con buena parte de la metafísica occidental. El desdibujamiento entre lo estructural y lo histórico que LaCapra plantea permite a su vez dar cuenta de cómo estas tesis de calado ontológico no pueden entenderse dejando de lado el contexto bélico indirectamente vivido por el filósofo francés. Tal y como revela nuestra lectura de sus tesis en torno a la negación del en-sí, a la intersubjetividad y a la aspiración a convertirse en en-sí-para-sí por parte de la conciencia impura, estas ideas deben contextualizarse en relación a la tradición filosófica a la que pertenece y a la forma en que su pensamiento metaboliza las experiencias de su tiempo histórico. La potencialidad exegética que acompaña a la noción de trauma, tal y como es prefigurada a través de las distinciones conceptuales de LaCapra, nos ofrece herramientas conceptuales para desentrañar esa compleja imbricación entre el texto sartreano y su contexto.

\section{REFERENCIAS BIBLIOGRÁFICAS}

ARIAS, M. 1987: Jean-Paul Sartre y la dialéctica de la cosificación. Madrid: Cincel. ARONSON, R. (1971): «Sartre's Individualist Social Theory», en Telos. No. 16, pp. 68-91.

AUDRY, C. 1975: Sartre y la realidad humana. Madrid: EDAF.

BEAUVOIR, S. 1961: Jean Paul Sartre versus Maurice Merleau-Ponty. Buenos Aires: Siglo XX.

CARUTH, C. 2017: Unclaimed Experience: Trauma, Narrative, and History. Baltimore: John Hopkins University Press.

COHEN-SOLAL, A. 2005: Sartre 1905-1980. Madrid: Edhasa.

CROWELL, S. 2012: The Cambridge Companion to Existentialism. Cambridge: Cambridge University Press.

DAVIS, C. (2007): «Sartre's Living Dead», en Haunted Subjects. Deconstruction, Psychoanalysis and the Return of the Dead. Hampshire: Palgrave, pp. 43-65.

DAVIS, C. 2018: Traces of War. Interpreting Ethics and Trauma in Twentieth-Century French Writing. Liverpool: Liverpool University Press.

DERRIDA, J. 1997: Mal de archivo. Una impresión freudiana. Madrid: Trotta.

JAMESON, F. (1971): «Sartre and History», en Marxism and Form. TwentiethCentury Dialectical Theories of Literature. New Yersey: Princeton University Press, pp. 206-305.

JAY, M. (1984): «From Totality to Totalization: The Existentialist Marxism of JeanPaul Sartre», en Marxism and Totality. The Adventures of a Concept from Lukács to Habermas. California: University of California Press, pp. 331-360. 
KLEINBERG, E. (2006): «Jean-Paul Sartre», en Generation Existential. Heidegger Philosophy in France, 1927-1961. Ithaca: Cornell University Press.

KRAMER, L. (1989): «Literature, Criticism, and Historical Imagination: The Literary Challenge of Hayden White and Dominick LaCapra», en HUNT, L. (ed.) The New Cultural History. Berkeley: University of California Press, pp. 97-130.

LACAPRA, D. 1978: A Preface to Sartre. London: Methuen \& Co.

LACAPRA, D. 1983: Rethinking Intellectual History: Texts, Contexts, Language. Ithaca: Cornell University Press.

LACAPRA, D. (1992): «Representing the Holocaust: Reflections on the Historians' Debate», en FRIEDLÄNDER, S. (ed.) Probing the Limits of Representation. Nazism and the Final Solution. Cambridge: Havard University Press, pp. 108127.

LACAPRA, D. 1998: History and Memory after Auschwitz. Ithaca: Cornell University Press.

LACAPRA, D. 2004: History in Transit. Experience, Identity, Critical Theory. Ithaca and London: Cornell University Press.

LACAPRA, D. 2009: History and its limits. Human, animal, violence. Ithaca and London: Cornell University Press.

LACAPRA, D. 2014: Writing History, Writing Trauma. Baltimore: The John Hopkins University Press.

LACAPRA, D. 2016: Historia, literatura, teoría crítica. Barcelona: Bellaterra.

LACAPRA, D. 2018: Understanding Others. Peoples, Animals, Pasts. Ithaca and London: Cornell University Press.

LEVY, B. 2001: El siglo de Sartre. Barcelona: Ediciones b.

MORENO, C. 2000: Fenomenología y Filosofia Existencial. Vol II. Madrid: Sintesis.

NORRIR, C. 1982: Deconstruction. Theory \& Practice. New York and London: Routledge.

OVEGAARD, S. (2013): «The Look», en CHURCHIL, S; REYNOLDS, J. (eds.): Jean-Paul Sartre: Key Concepts. New York and London: Routledge, pp. 106117.

POSTER, M. 1973: Existential Marxism in Postwar France. From Sartre to Althusser. New Jersey: Princeton University Press.

RICHMOND, S. (2013): «Nothingness and Negation», en CHURCHIL, S; REYNOLDS, J. (eds.): Jean-Paul Sartre: Key Concepts. New York and London: Routledge, pp. 93-105.

SARTRE, J. P. 1960: La república del silencio. Buenos Aires: Losada. SARTRE, J. P. 1949: Les situations III. Paris: Gallimard.

SARTRE, J. P. 2003: La trascendencia del ego. Madrid: Síntesis. SARTRE, J. P. 1996: La trascendance de l'ego. Paris: Vrin.

SARTRE, J. P. 2004: El existencialismo es un humanismo. Madrid: Edhasa. SARTRE, J. P. 1945: L'existentialism est un humanismo. Paris: Nagel.

SARTRE, J. P. 2013: El Ser y la Nada. Ensayo de ontología fenomenológica. Buenos Aires: Losada. SARTRE, J.P. 1943. L'être et le néant. Essai d'ontologie phénomenologique. Paris: Gallimard. 
SARTRE, J.P. 2008: Between Existentialism and Marxism. London and New York: Verso.

SARTRE, J.P. 2008: La Náusea. Buenos Aires: Buenos Aires.

SARTRE, J. P. 1938: La Nausee. Paris: Gallimard.

SARTRE, J.P. 2017: Las palabras. Buenos Aires: Losada. SARTRE, J. P. 1964: Let Mots. Paris: Gallimard.

SARTRE; J. P. 2005: A puerta cerrada. Buenos Aires: Losada.

RAFAEL PÉREz BAQUERo es Doctor en Filosofía por la Universidad de Murcia.

Lineas de investigación

Filosofía contemporánea, Filosofía de la historia, Estudios de memoria

Publicaciones recientes

2021: Trauma, memoria y duelo. Una aproximación filosófica a las relaciones entre memoria e historia, Granada: Comares.

2021: «From Psychoanalysis to Cultural Trauma. Narrating Legacies of Collective Suffering», Critical Horizons, 16.

Correo electrónico: rafaelperbaq@gmail.com 
